John E. Tetzlaff MD, Helen J. Yoon MD, Michael Walsh MD

\title{
Regional anaesthetic technique and the incidence of tourniquet pain
}

The influence of regional anaesthetic technique on the incidence of lower extremity tourniquet pain was evaluated. We studied 60 patients undergoing orthopaedic procedures of the lower extremity with the use of a pneumatic tourniquet and anticipated inflation of $60 \mathrm{~min}$ or longer. Three different anaesthetic techniques were selected by random card draw: spinal anaesthesia (SAB) with plain $0.5 \%$ bupivacaine $(15 \mathrm{mg}$ ) and $0.2 \mathrm{mg}$ epinephrine added, lumbar epidural anaesthesia (EA) with $2 \%$ mepivacaine and 1:200,000 epinephrine added, and epidural anaesthesia (AEA) with the same solution alkalinized with bicarbonate. Onset and level of sensory blockade were determined by loss of painful sensation to pinprick. The incidence of tourniquet pain was determined at 15-min intervals or by patient complaint, by an observer unaware of group. Time to onset of pain, amount of treatment (iv fentanyl), and sensory level at the time of pain were determined. The $S A B$ was compared with $E A$ and $A E A$, and $E A$ was compared with $A E A$. The $S A B$ group was older. The sensory level achieved and duration of tourniquet inflation did not differ among groups. The incidence of tourniquet pain was lower with $S A B$ than with $E A$ and lower with $A E A$ than with $E A$. There was no difference between $S A B$ and AEA. This study demonstrated a lower incidence of tourniquet pain with spinal anaesthesia than with epidural anaesthesia to the same sensory level. However, this advantage is eliminated if the epidural anaesthetic was performed with an alkalinized local anaesthetic.

Nous avons évalué l'influence des techniques d'anesthésie régionale sur la douleur causée par un garrot au niveau du membre

\section{Key Words}

ANAESTHETIC TECHNIQUE: regional, spinal, epidural; ANAESTHETICS, LOCAL: bupivacaine, mepivacaine.

From the Department of General Anesthesia, The Cleveland Clinic Foundation, 9500 Euclid Avenue, Cleveland, Ohio 44195.

Presented in part at the Canadian Anaesthetists Society Meeting, Quebec, Canada (June 19, 1992) and the American Society of Regional Anesthesia Meeting in Tampa, Florida (April, 1992).

Accepted for publication 8th April, 1993. inférieur. Nous avons étudié 60 patients subissant une intervention orthopédique du membre inférieur avec utilisation d'un garrot pneumatique prévu pour 60 minutes ou plus. Trois techniques anesthésiques différentes ont été utilisées aléatoirement: anesthésie rachidienne $(A R)$ avec de la bupivacaine $0,5 \%$ (15 mg) adrénalinée extemporanément à une concentration de 1:200 000, anesthésie épidurale lombaire (AE) avec 2\% mépivacaine et 1:200 000 d'adrénaline et anesthésie épidurale avec la même solution mais alcalinisée au bicarbonate (AEA). Le début et le niveau du bloc sensitif sont déterminés par la perte de sensation à la piqure. Lincidence de la douleur du garrot a été évaluée à 15 minutes dintervalle ou en cas de plainte du patient par un observateur ignorant la technique d'anesthésie. Le délai d'apparition de la douleur, limportance du traitement (Fentanyl iv) et le niveau sensitif au moment des plaintes ont été notés. L'AR est comparée à l'AE et à l'AEA, et l'AE est comparée à l'AEA. Le groupe AR se compose de patients plus âgés. Le niveau sensitif du bloc obtenu et la durée du garrot sont semblables dans tous les groupes. Lincidence de la douleur due au garrot est plus basse avec l'AR par rapport à l'AE, et plus basse avec l'AEA qu'avec l'AE. Il n'y a pas de différence entre l'AR et l'AEA. Cette étude démontre une incidence plus basse de douleur due au garrot avec l'anesthésie rachidienne qu'avec l'anesthésie épidurale pour un même niveau de bloc sensitif. Cependant, cet avantage de l'AR est perdu si l'anesthésie épidurale se réalise avec un anesthésique local alcalinisé.

Pneumatic tourniquets are often used to provide a bloodless operating field during lower-extremity surgery. Their use is associated with a variety of intraoperative effects, including hypertension, tachycardia, increased temperature during general anaesthesia, and pain during otherwise adequate regional anaesthesia. ${ }^{1-8}$ During regional anaesthesia, a poorly localized, diffuse pain is felt by the patient at variable times after tourniquet inflation, despite adequate sensory blockade. This tourniquet pain is related to the duration of inflation and not to inflation pressure, although greater pain has been reported when larger cuffs are used. ${ }^{9}$

Different regional anaesthetic techniques result in different incidences of tourniquet pain. Spinal anaesthesia 
has been shown to be more effective in preventing tourniquet pain than epidural anaesthesia. ${ }^{10}$ With spinal anaesthesia, bupivacaine is superior to tetracaine. ${ }^{7,11}$ The addition of glucose to spinal anaesthesia is associated with a higher incidence of tourniquet pain, ${ }^{5}$ while a variety of additives, morphine, ${ }^{12}$ and clonidine ${ }^{13}$ decrease the incidence.

Alkalinization of local anaesthetics has been shown to decrease the latency to onset of a variety of regional anaesthetics including epidural anaesthesia. ${ }^{15,16}$ Other clinical effects include wider spread of blockade and increased duration. ${ }^{17}$ The purpose of this study was to determine whether the alkalinization of mepivacaine alters the incidence of tourniquet pain compared with epidural anaesthesia without added bicarbonate and spinal anaesthesia.

\begin{abstract}
Methods
After obtaining the permission of the Institutional Review Board, written informed consent was obtained from three groups of 20 patients each scheduled to undergo orthopaedic surgery on the lower extremity using a pneumatic tourniquet. Only patients in whom the anticipated inflation time was greater than $60 \mathrm{~min}$ were selected. The patients were randomized by card draw into three groups, spinal anaesthesia (I) with $15 \mathrm{mg}$, plain bupivacaine with $0.2 \mathrm{mg}$ epinephrine or epidural anaesthesia with $20 \mathrm{ml}$, $2 \%$ mepivacaine, 1:200,000 epinephrine with either saline (II) or bicarbonate $1 \mathrm{mEq} \cdot \mathrm{ml}^{-1}$ (III) added. The $\mathrm{pH}$ and $\mathrm{PCO}_{2}$ of these solutions were measured in a nonclinical setting. All patients receiving an epidural anaesthetic had a catheter placed and the local anaesthetic (10 $\mathrm{ml})$ was repeated if two-segment sensory regression was reached before the conclusion of surgery. The level of regional block and the time to onset of anaesthesia were determined by an observer unaware of the patient's group. Sensory onset was defined as a lack of awareness of sharp sensation from pinprick at $\mathrm{L}_{1}$. Motor onset was defined as an inability to flex the hips or knees. Pain was evaluated by questions asked by an observer unaware of the treatment group. If pain was reported, the level of block was assessed to rule out failed or resolved regional block and the pain was treated with fentanyl $\mathbf{5 0}$ $\mathrm{mg}, i v$. The duration of tourniquet inflation when pain was detected was recorded. Cases with pain-free tourniquet times of less than $60 \mathrm{~min}$ were excluded. Groups were compared with Fisher's exact test, Wilcoxon's rank sum test, and paired $t$ test with Bonferroni's correction for comparison of multiple groups and considered significant at $P<0.05$.
\end{abstract}

\section{Results}

Twenty patients were acquired for each group. One pa- tient from Groups I, and II and five patients from Group III were excluded for having tourniquet inflation of less than $60 \mathrm{~min}$ and no tourniquet pain. The demographic characteristics (age, height, weight, ASA physical status) were comparable among all groups except for an older age in Group I (spinal) compared with the other three groups. The $\mathrm{pH}$ of the solutions was 5.56 for mepivacaine with saline and 7.31 for mepivacaine with bicarbonate averaged over three determinations. The $\mathrm{PCO}_{2}$ was 210 $\mathrm{mmHg}$ in the alkalinized group over three determinations.

The sensory level achieved with the blocks was comparable among procedures. There were no failed blocks or complications. Four patients in Group II required redosing of the epidural before the conclusion of surgery for two-segment regression and five in Group III. This was not different. The mean tourniquet times were not different among groups, nor was the time to onset of tourniquet pain. The incidence of tourniquet pain was higher in the plain epidural groups (II) than in both the spinal Group (I) $(P<0.01)$ and the alkalinized epidural Group (III) $(P<0.05)$ (Table I). There was no difference in tourniquet pain between spinal and alkalinized epidural groups. Alkalinization accelerated the onset of both motor and sensory block with epidural anaesthesia (Table II).

\section{Discussion}

These results establish that the incidence of tourniquet pain is related to anaesthetic technique. When compared with conventional epidural anaesthesia, spinal block appears to be superior in the prevention of tourniquet pain. However, when the epidural technique is performed with alkalinized mepivacaine, this advantage is eliminated. This suggests an improved quality of epidural anaesthesia when performed with alkalinized mepivacaine.

Although this study confirms the influence of anaesthetic technique on the incidence of tourniquet pain, the exact cause of pain remains unclear. In each patient with pain, the sensory level of the block was higher than the dermatomes involved in either the surgery or even the tourniquet itself. Many theories have been advanced to explain the phenomenon. Because of the poorly localized quality of the pain, Hagenouw ${ }^{9}$ proposed a direct ischaemic effect on the nerve trunk, or the sensory innervation of the major arteries due to local products of anaerobic metabolism. This idea is supported by the absence of a similar pain during aortic clamping for peripheral vascular surgery and the slow resolution of the pain during reperfusion after tourniquet release.

Another explanation concerns the differential blockade of different fibre types. Rocco ${ }^{17}$ found a differential zone between the level of anaesthesia to pinprick and light 
TABLE I Incidence of tourniquet pain

\begin{tabular}{llllll}
\hline & & $\begin{array}{l}\text { Level } \\
\text { thoracic } \\
\text { mean (SEM) }\end{array}$ & $\begin{array}{l}\text { Tourniquet } \\
\text { time (min) } \\
\text { mean (SD) }\end{array}$ & $\begin{array}{l}\text { Time to } \\
\text { tourniquet } \\
\text { pain (min) } \\
\text { mean (SD) }\end{array}$ & $\begin{array}{l}\text { Tourniquet } \\
\text { pain }\end{array}$ \\
\hline Spinal (I) & 19 & $7.7(1.4)$ & $122.1(21.8)$ & 77 & 1 \\
Epidural (II) & 19 & $7.3(2.5)$ & $112.2(33.4)$ & $75.6(28.4)$ & 9 \\
Epidural (II) & 15 & $7.5(1.6)$ & $103.6(26.8)$ & 60 & 1 \\
& & & & & \\
\hline & Tourniquet & & Test & \\
& pain & $P$ value & Student's t & \\
\hline & I $<$ II & $P=0.008$ & Fisher's exact & & \\
& III $<$ II & $P=0.047$ & Fisher's exact & & \\
& II $<$ III & $P=1.00$ & & \\
\hline
\end{tabular}

TABLE II Onset times

\begin{tabular}{llcc}
\hline & Number & $\begin{array}{l}\text { Motor (min) } \\
\text { Mean (SD) }\end{array}$ & $\begin{array}{l}\text { Sensory (min) } \\
\text { Mean (SD) }\end{array}$ \\
\hline Epidural (II) saline & 19 & $16.7(4.9)$ & $10.8(3.9)$ \\
Epidural (III) $\mathrm{HCO}_{3}$ & 15 & $6.0(3.2)$ & $3.3(1.2)$ \\
\hline
\end{tabular}

Motor III $<$ II $P<0.001$; Sensory III $<$ II $P<0.00$ I; Student's t test.

touch during spinal anaesthesia. While the level of anaesthesia to pinprick had no correlation to tourniquet pain, assessment of level of anaesthesia to light touch was a good indicator of tourniquet pain. The zones of differential blockade are even greater during regression of the block which is more likely near the conclusion of surgery when tourniquet pain is most often reported. Regression of the block was not an issue in our patients.

On a more basic level, the gate theory of Melzack and Wall may be involved. ${ }^{18}$ Larger nerve fibres are postulated to inhibit the central effect of smaller A-delta and C-fibres in the dorsal horn of the spinal cord, and tourniquet pain is accentuated by effective blockade of larger A-beta fibres. Repetitive stimulation accentuates the impulses of the smaller fibres, and the repetitive stimulus may be the tourniquet.* Repetitive stimulus may even penetrate marginal areas of the block. ${ }^{17}$ This presents the combination of increases nociceptive conduction (Adelta, C-fibres) with decreased inhibitory modulation (Abeta). In the presence of repetitive nociceptive stimulus, fibres normally conducting only touch may become nociceptive. ${ }^{19}$ This combined theory helps to explain the absence of a positive effect of sympathectomy on the incidence of tourniquet pain. ${ }^{20}$ Chabel $^{21}$ provided support-

* Strichartz G. Zimmerman M: An explanation for pain originating from tourniquets during regional anesthesia. Reg Anesth 1984; 9: 44-5. ing evidence for this theory with microfilament recordings showing slow firing, slow conductance activity in fibres not active before tourniquet inflation in animals. The recordings did not indicate, however, whether this activity followed somatic nerves or partially or completely entered the sympathetic system.

Considering the complex mechanism of tourniquet pain, it is not surprising that its incidence is influenced by anaesthetic technique. With spinal anaesthesia, a number of variables has been established. Bridenbaugh ${ }^{5}$ compared spinal anaesthesia with bupivacaine with and without added glucose. The incidence of tourniquet pain was higher in the glucose (hyperbaric) group and seemed to be related to the density of the lower segments of the block. Bonnet ${ }^{8}$ did a similar study with tetracaine and could not demonstrate a difference. Concepcion ${ }^{7}$ demonstrated an advantage with bupivacaine compared with tetracaine. They postulated that small $\mathrm{C}$-fibres (known to be responsible for slow conductance and poorly localized pain) became unblocked sooner than other fibre types with tetracaine and not with bupivacaine. Evidence of differential sensitivities of C-fibres in vitro by Gissen ${ }^{22}$ supports this hypothesis. During regression of the block, tetracaine-blocked $\mathrm{C}$-fibres became active sooner than bupivacaine blocked fibres. Stewart ${ }^{6}$ also supported this hypothesis with in vitro results that establish an enhanced frequency-dependent block of $\mathrm{C}$-fibres with bupivacaine compared with tetracaine. Increased stimulus frequency is known to occur with tourniquet inflation. ${ }^{21}$

The favourable effect of alkalinization of epidural mepivacaine on the incidence of tourniquet pain may also fit these explanations. Alkalinization decreases the onset time of epidural anaesthesia, ${ }^{14,23,24}$ specifically epidural mepivacaine. ${ }^{14}$ This effect is mediated by an increased concentration of the non-ionized form of the local anaesthetic molecule which facilitates nerve cell membrane penetration. An increase in extracellular $\mathrm{PCO}_{2}$ encour- 
ages intracellular diffusion of $\mathrm{CO}_{2}$ which would decrease the intracellular $\mathrm{pH}$ and facilitate the inward diffusion of the non-ionized form by increasing the concentration gradient. ${ }^{25}$ Differences in $\mathrm{PCO}_{2}$ between alkalinized solutions may explain the varied results despite similar $\mathrm{pH}$ among different studies.

Some studies have shown other influences on the quality of the block in addition to the effect on the onset time of some local anaesthetics. McMorland, ${ }^{23,24}$ with epidural bupivacaine, and Candido, ${ }^{16}$ with mepivacaine for plexus blockade, found an increased duration of blockade. Cousins and Bromage ${ }^{26}$ found prolonged duration as well as increased density and spread of caudal epidural anaesthesia, which is thought to be mediated by a mechanism analogous to bicarbonate alkalinization. The mechanism of altered block quality is unknown but may be related to biochemical factors acting during the initial onset of the block. If not alkalinized, the acidic local anaesthetic must be buffered in the extracellular space. While this occurs, diffusion may decrease the effective delivered concentration. It may be that alkalinized solutions deliver higher concentrations to the ultimate destinations, and because fibre types have concentrationspecific block characteristics, more complete blockade may occur. Alternatively, frequently-specific blockade may be facilitated.

This study confirmed the lower incidence of tourniquet pain with spinal anaesthesia than with epidural anaesthesia found by Pitkänen. ${ }^{10}$ However, alkalinization of epidural mepivacaine eliminated this difference. It is unclear if this would have been the case in the Pitkänen patients, because etidocaine, like bupivacaine, cannot be as effectively alkalinized as mepivacaine because of precipitation. The decrease in tourniquet pain achieved with additives to local anaesthetics for central blocks is not surprising: it occurs with clonidine ${ }^{12}$ and morphine. ${ }^{11}$ The favourable influences of these additives in the case of adrenergic agonists is explained by the suppression of nociceptive transmission at the spinal cord level with adrenergic agonist injection independent of local anaesthetic. ${ }^{27}$ There may be an additive or even synergistic effect. The superiority of intrathecal local anaesthetic may abe related to the higher relative concentration of local anaesthetic delivered directly to nervous tissue without the diffusion necessary for epidural blockade.

In summary, the incidence of tourniquet pain is specific to the regional anaesthetic technique. Spinal anaesthesia with isobaric bupivacaine with epinephrine is superior to epidural anaesthesia with mepivacaine and epinephrine, unless the epidural solution is alkalinized. Increased density or decreased differential blockade may be the effect of alkalinization.

\section{References}

1 Kaufman RD, Walts $L F$. Tourniquet-induced hypertension. Br J Anaesth 1982; 54: 333-6.

2 Valli $H$, Rosenberg $P H$. Effects of three anaesthesia methods on hemodynamic responses connected with the use of thigh tourniquet in orthopedic patients. Acta Anaesthesiol Scand 1985; 29: 142-7.

3 Valli H, Rosenberg PH, Kyttä J, Nurminen M. Arterial hypertension associated with the use of a tourniquet with either general or regional anaesthesia. Acta Anaesthesiol Scand 1987; 31: 279-83.

4 Ebert $L D$, Deas $T C$. Cause of pain from a pneumatic tourniquet during spinal anesthesia. Anesthesiology 1962; 23: 287-90.

5 Bridenbaugh PO, Hagenouw RRPM, Gielen MJM, Edström $H H$. Addition of glucose to bupivacaine in spinal anesthesia increases incidence of tourniquet pain. Anesth Analg 1986; 65: 1181-5.

6 Stewart A, Lambert DH, Concepcion MA, et al. Decreased incidence of tourniquet pain during spinal anesthesia with bupivacaine. Anesth Analg 1988; 67: 833-7.

7 Concepcion MA, Lambert DH, Welsh KA, Covino BG. Tourniquet pain during spinal anesthesia: a comparison of plain solutions of tetracaine and bupivacaine. Anesth Analg 1988; 67: 828-32.

8 Bonnet F, Zozime JP, Marcandoro J, Buisson VB, Touboul $C$, Saada $M$. Tourniquet pain during spinal anesthesia. Hyperbaric versus isobaric tetracaine. Reg Anesth 1988; 13: 29-33.

9 Hagenouw RRPM, Bridenbaugh PO, van Egmond J, Stuebing $R$. Tourniquet pain: a volunteer study. Anesth Analg 1986; 65: 1175-80.

10 Pitkänen MJ, Tuominen MK, Rosenberg PH. Bupivacaine spinal anesthesia compared with etidocaine epidural anesthesia for orthopedic surgery in old and young patients. Reg Anesth 1985; 10: 62-7.

11 Rocco $A G$, Concepcion $M$, Sheskey MC, Murray E, Edstrom $H$, Covino $B G$. A double-blind evaluation of intrathecal bupivacaine without glucose and a standard solution of hyperbaric tetracaine. Reg Anesth 1984; 9: $1-7$.

12 Touminen $M$, Valli $H$, Kalso $E$, Rosenberg $P H$. Efficacy of $0.3 \mathrm{mg}$ morphine intrathecally in preventing tourniquet pain during spinal anaesthesia with hyperbaric bupivacaine. Acta Anaesthesiol Scand 1988; 32: 113-6.

13 Bonnet F, Diallo A, Saada M, Belon M, Guilbaud M, Boico $O$. Prevention of tourniquet pain by spinal isobaric bupivacaine with clonidine. Br J Anaesth 1989; 63: 93-6.

14 DiFazio CA, Carron H, Grosslight KR, Moscicki JC, Bolding WR, Johns RA. Comparison of $\mathrm{pH}$-adjusted lidocaine solutions for epidural anesthesia. Anesth Analg 1986; 65: 760-4.

15 Capogna $G$, Celleno $D$, Tagariello $V$. The effect of $\mathrm{pH}$ ad- 
justment of $2 \%$ mepivacaine on epidural anesthesia. Reg Anesth 1989; 14: 121-3.

16 Candido KD, Raza SM, Vasireddy $A R$. PH adjusted mepivacaine for lower extremity conduction anesthesia. Reg Anesth 1989; 14: A68.

17 Rocco AG, Raymond SA, Murray E, Dhingra U, Freiberger $D$. Differential spread of blockade of touch, cold, and pinprick during spinal anesthesia. Anesth Analg 1985; 64: 917-23.

18 Melzack $R$, Wall PD. Pain mechanisms: a new theory. Science 1965; 150: 971-9.

19 Campbell JN, Raja SN, Meyer RA, Mackinnon SE. Myelinated afferents signal the hyperalgesia associated with nerve injury. Pain 1988; 32: 89-94.

20 Farah RS, Thomas PS. Sympathetic blockade and tourniquet pain in surgery of the upper extremity. Anesth Analg 1987; 66: 1033-5.

21 Chabel C, Russell LC, Lee $R$. Tourniquet-induced limb ischemia: a neurophysiologic animal model. Anesthesiology 1990; 72: 1038-44.

22 Gissen AJ, Covino BG, Gregus J. Differential sensitivities of mammalian nerve fibers to local anesthetic agents. Anesthesiology 1980; 53: 467-74.

23 McMorland GH, Douglas MJ, Jeffery WK, et al. Effect of $\mathrm{pH}$-adjustment of bupivacaine on onset and duration of epidural analgesia in parturients. Can Anaesth Soc J 1986; 33: 537-41.

24 McMorland GH, Douglas MJ, Kim JHK, et al. The effect of $\mathrm{pH}$-adjustment of bupivacaine on onset and duration of epidural anaesthesia for Caesarean section. Can J Anaesth 1988; 35: 457-61.

25 Ackerman WE, Juneja MM, Denson DD, et al. The effect of $\mathrm{pH}$ and $\mathrm{PCO}_{2}$ on epidural analgesia with $2 \% 2-$ chloroprocaine. Anesth Analg 1989; 68: 593-8.

26 Cousins MJ, Bromage PR. A comparison of the hydrochloride and carbonated salts of lignocaine for caudal anesthesia in out-patients. Br J Anaesth 1971; 43: 1149-54.

27 Reddy H, Maderdrut JL, Yaksh TL. Spinal cord pharmacology of adrenergic agonist-mediated antinociception. $J$ Pharm Exp Ther 1980; 213: 525-33.

28 Collins JG, Kitahata LM, Mitsumoto M, Homma E, Suzukawa $M$. Spinally administered epinephrine suppresses noxiously evoked activity of WDR neurons in the dorsal horn of the spinal cord. Anesthesiology 1984; 60: 269-75. 